American Journal of Infectious Diseases 6 (1): 18-23, 2010

ISSN 1553-6203

(C) 2010 Science Publications

\title{
Methicilin Resistant Staphylococcus aureus Carriage amongst Healthcare Workers of the Critical Care Units in a Nigerian Hospital
}

\author{
${ }^{1}$ A. Fadeyi, ${ }^{2}$ B.O. Bolaji, ${ }^{2}$ O.O. Oyedepo, ${ }^{3}$ O.O. Adesiyun, ${ }^{3}$ M.A.N. Adeboye, ${ }^{4}$ T.O. Olanrewaju, \\ ${ }^{4}$ A. Aderibigbe, ${ }^{4}$ A.K. Salami, ${ }^{4}$ O.O. Desalu, ${ }^{1}$ A. Fowotade, ${ }^{1}$ C. Nwabuisi, \\ ${ }^{1}$ A.A. Akanbi II, ${ }^{1}$ R.A. Raheem and ${ }^{1}$ A. Olalere \\ ${ }^{1}$ Department of Medical Microbiology and Parasitology, \\ ${ }^{2}$ Department of Anaesthesia, \\ ${ }^{3}$ Department of Paediatrics and Child Health, \\ ${ }^{4}$ Department of Internal Medicine, \\ University of Ilorin Teaching Hospital, PMB 1459, Ilorin, Nigeria
}

\begin{abstract}
Problem statement: Methicilin Resistant Staphylococcus Aureus (MRSA) Nosocomial Infection (NI) outbreaks and prevalence among various populations are well reported in literature particularly for developed countries. NI due to MRSA is a known cause of increased hospital stay, cost, morbidity and mortality especially among the critically ill. There is paucity of information on MRSA in developing nations including the carriage by critical healthcare givers who are potential transmitters. In most hospital in developing countries like Nigeria, there is neither surveillance system or control policy for MRSA. Approach: We screened healthcare workers in the critical care units of the University of Ilorin Teaching Hospital (UITH), Ilorin, Nigeria for MRSA and determined vancomycin susceptibility of the isolates. Swabs of both anterior nares and web spaces of the hands were taken, transported and incubated in Tween 80 at $35^{\circ} \mathrm{C}$ overnight aerobically before inoculation onto Mannitol Salt Agar (MSA). Inoculated MSA were incubated aerobically at $35^{\circ} \mathrm{C}$ for $18-24 \mathrm{~h}$. Staphylococcus aureus was identified as Gram positive cocci with positive catalase, coagulase and DNAse test. MRSA were identified by combined oxacillin and cefoxitin discs diffusion method. Sensitivity to vancomycin was by vancomycin discs diffusion and vancomycin agar screen plating. Results: Of the 198 healthcare workers screened, 104 had MRSA either in the nose, hand or both giving a carriage rate of $52.5 \%$. Nasal carriage $(38.9 \%)$ was higher than hand $(25.3 \%)$. Doctors $(22.7 \%)$ and Nurses $(16.7 \%)$ were the predominant carriers. MRSA isolates were resistant to commonly available antibiotics. Only $1(1.3 \%)$ of the nasal isolates was vancomycin resistant. Conclusion: MRSA carriage among healthcare workers in the critical care units of the Nigerian hospital is high with doctors and nurses being the major carriers. The MRSA isolates were multi-drug resistant which may lead to increased morbidity and mortality if transmitted to the critically-ill. There is need for MRSA control policies in hospitals with settings of our type.
\end{abstract}

Key words: Methicilin, resistance, Staphylococcus aureus, critically-ill, healthcare workers, Nigeria

\section{INTRODUCTION}

Methicilin-Resistant Staphylococcus Aureus (MRSA) has become endemic worldwide within the past two decades (Chaix et al., 1999). There is Hospital-Acquired MRSA (HA-MRSA) as well as Community-Acquired MRSA (CA-MRSA) strains and infections (Albrich and Harbarth, 2008). MRSA together with Vancomycin-Resistant Staphylococcus Aureus (VRSA), Extended Spectrum $\beta$ Lactamase
(ESBL) producing Gram Negative Bacilli (GNB) and certain other GNB are classified as Multi-Drug Resistant Organisms (MDRO) including multi-drug resistant Mycobacterium tuberculosis (Siegel et al., 2006). MRSA strains are resistant to an array of antibiotics for which reason the treatment of infections due to this organism is always a challenge, more so when the critically ill patients are infected.

The spectrum of infections due to MRSA varies from mild skin infections to serious and invasive

Corresponding Author: A. Fadeyi, Department of Medical Microbiology and Parasitology,

University of Ilorin Teaching Hospital, PMB 1459, Ilorin, Kwara State, Nigeria 
diseases such as septicaemia, pneumonia, endocarditis, deep-seated abscesses and toxinoses including food poisoning and toxic shock syndrome (Tenover and Gaynes, 2000; Holmes et al., 2005). Infections due to MRSA are associated with worse outcome in addition to prolonged hospital stay, higher cost of treatment and increased mortality (Shorr et al., 2006; Zahar et al., 2005).

A previous laboratory based study at the University of Ilorin Teaching Hospital (UITH), Ilorin, Nigeria reported the prevalence of MRSA as $34.7 \%$ of all staphylococcal isolates of which approximately $13.7 \%$ were recovered from patients in the intensive care unit (Taiwo et al., 2004). Other studies in Nigeria indicated that MRSA is not uncommon in our environment (Azeez-Akande et al., 2008; Kesah et al., 2003; Adesida et al., 2005). Policies towards the control of spread and infections due to this organism are therefore desirable and will best be formulated when it is given a holistic approach.

The role of MRSA carriers in the transmission of this pathogen is critical. A carrier of MRSA is a person who is colonized by the organism in the nares (nose), sputum, urine, an open wound, in the stool or on the skin without clinical manifestations of disease (MRSA, 2010). Such carriers may transmit the organism to another person through direct contact, usually through colonized hands and aerosolization following sneezing. Therefore, healthcare givers who are at the interface between the hospital and the community may serve as agents of cross-transmission of HA-MRSA and CA-MRSA (Albrich and Harbarth, 2008).

The necessity of mass screening of health care givers for MRSA has been extensively debated with regards to advantages, disadvantages and ethical issues (Simpson et al., 2007; Brady, 2008). Nonetheless, nosocomial transmissions of MRSA from and through health care givers to hospitalised patients have been documented and may be greater than previously thought (Albrich and Harbarth, 2008; Vonberg et al., 2006). Similarly, screening and eradication of MRSA from colonized healthcare workers have been recognised and recommended as an important part of a comprehensive infection control policy for this organism (Herwaldt, 1999). This study therefore aimed at establishing the carriage rate of MRSA among healthcare workers in the critical care units of UITH, Ilorin, Nigeria. The outcome may be useful for formulating MRSA control policy for our hospital and others in similar settings.

\section{MATERIALS AND METHODS}

This study was conducted at UITH, Ilorin, Nigeria between December, 2009 and February, 2010. The hospital is a tertiary health care facility with 450 beds and an annual average of 10,000 and 12,000 admissions and outpatient hospital visits, respectively, in the last five years. All consenting staff working in the hospital units involved in the management of critically ill patients (intensive care unit (adult), dialysis/renal unit and neonatal intensive care unit) and students (Medical and Nursing) on clinical rotation to the units were randomly recruited into the study. The study was approved by the ethical review committee of the hospital.

The age, sex, work category, time of employment, duration of working in the critical care unit, history of admission, current skin infection/other illness and other relevant information about the participants were obtained in a pro forma designed for this purpose. Swabs of both anterior nares of consenting persons were taken with a sterile swab stick moistened with sterile physiological saline and transported in Tween 80 to the Microbiology laboratory unit of the hospital for analysis. Similar swabs of web spaces of the hands were also taken after at least $30 \mathrm{~min}$ of the last hand wash.

The swabs in Tween 80 were incubated at $35^{\circ} \mathrm{C}$ overnight before being inoculated onto Mannitol Salt Agar (MSA). Inoculated MSA were incubated at $35^{\circ} \mathrm{C}$ for 18-24 h. Gram positive cocci isolates which were catalase, coagulase and deoxyribonuclease positive, using standard techniques (Cheesbrough, 2000), were identified as Staphylococcus aureus and screened for methicillin resistance by modified Kirby-Bauer method (Bauer et al., 1966) using oxacillin $(1 \mu \mathrm{g})$ and cefoxitin (30 $\mu \mathrm{g})$ discs on Mueller-Hinton Agar (MHA). The MHA on which oxacillin discs were applied was supplemented with $2 \% \mathrm{NaCl}$ and incubated aerobically for $24 \mathrm{~h}$ at $30^{\circ} \mathrm{C}$ while the one on which cefoxitin was placed was not supplemented with $\mathrm{NaCl}$ but incubated aerobically at $35^{\circ} \mathrm{C}$ for $18 \mathrm{~h}$. Isolates with both inhibition zone diameter $\leq 13$ and $\leq 21 \mathrm{~mm}$ around oxacillin and cefoxitin discs respectively were considered MRSA strains.

Screening for vancomycin susceptibility was also by the modified Kirby-Bauer method using vancomycin disc $(30 \mu \mathrm{g})$ on MHA incubated at $35^{\circ} \mathrm{C}$ for $24 \mathrm{~h}$. Isolates with inhibition zone diameter $\leq 7 \mathrm{~mm}$ around vancomycin disc were confirmed Vancomycin Resistant Staphylococcus Aureus (VRSA) if there was growth of at least a colony on vancomycin agar screen plate (Brain Heart Infusion agar containing $6 \mathrm{mg} \mathrm{L}^{-1}$ of vancomycin) after spot inoculation and aerobic incubation at $35^{\circ} \mathrm{C}$ for $24 \mathrm{~h}$. 
Antibiotic sensitivity of the MRSA isolates against erythromycin $(15 \mu \mathrm{g})$, chloramphenicol $(30 \mu \mathrm{g})$, cotrimoxazole $(1.25 / 23.75 \mu \mathrm{g})$, ceftriaxone $(30 \mu \mathrm{g})$, gentamycin $(10 \mu \mathrm{g})$, Amoxicillin/clavulanic acid $(30 \mu \mathrm{g})$ and ciprofloxacin $(5 \mu \mathrm{g})$ was determined by modified Kirby-Bauer method on MHA incubated at $35^{\circ} \mathrm{C}$ for 18-24 $\mathrm{h}$ and VRSA strains were similarly tested against quinupristin/dalfopristin (Synercid) $(15 \mu \mathrm{g})$.

All inocula on MHA were suspension of pure isolates in physiologic saline with density equivalent to a $0.5 \mathrm{McF}$ arland turbidity standard. Staphylococcus aureus ATCC 25923 was used as control. All antibiotic discs were also MAST diagnostic group (UK) products. Antibiotic sensitivity testing and result interpretation were according to BSAC standard (Andrews, 2008).

All data were entered into Microsoft excel 2007 data sheet, EPI info version 3.4.1, (CDC, Atlanta, Georgia, USA, 2007) and SPSS version 15 (SPSS Inc, Chicago, IL, USA, 2007) software statistical packages for analysis.

\section{RESULTS}

A total of 198 healthcare workers, age range 2050 years $($ mean $=33.7, \mathrm{SD}= \pm 8.7)$ were screened for MRSA. One hundred and six (53.5\%) were males and $92(46.5 \%)$ females. The mean number of years in service and duration of stay in the present unit of the participants was 7.8 and 6.1 respectively. Doctors (68) and Nurses (51) constituted the majority of subjects screened (Table 1).

In all, 104 healthcare workers were positive for MRSA either in the nose, hand or both giving a carriage rate of $52.5 \%$. The proportion of healthcare workers with nasal carriage was higher $(39.9 \%)$ than hand $(26.3 \%)$ with very few $(12.5 \%)$ of the subjects having dual (nose and hand) carriage (Table 2). Among the 106 males screened, $58.0(54.7 \%)$ were positive, compared to $45(48.9 \%)$ of the 92 females were positive giving a male to female carriage ratio of 1.3:1.

About half of the healthcare workers in all the units were MRSA carriers. The highest carriage $(58.6 \%)$ was recorded among the intensive care unit workers (Table 3). The distribution of MRSA carriage across cadre is presented in Table 4. Doctors (22.7\%) and Nurses (16.7\%) were the most colonized.

The MRSA isolates were multi-drug resistant (Table 5). They were resistant to erythromycin (\% resistance: Nose $=69.6 \%$, hand $=94.2 \%$ ), Cotrimoxazole $(\%$ resistance: Nose $=98.7 \%$, hand $=$ $100 \%$ ), Chloramphenicol (\% resistance: Nose $=89.9 \%$, hand $=75.0 \%)$ and Ceftraizone $(\%$ resistance: Nose $=98.7 \%$, hand $=73.1 \%$ ) but slightly sensitive to Ciprofoxacin $(\%$ sensitive: Nose $=59.5 \%$, hand $=$ $65.4 \%)$ and amoxyclavulanate (\% sensitive: Nose $=$
$89.9 \%$, hand $=86.5 \%$ ). While MRSA isolates of nose were resistant to Gentamicin (\% Resistance: 63.3\%), those of the hand were marginally sensitive (\% sensitive: $65.4 \%)$. Only $1(1.3 \%)$ of the nasal isolates was resistant to vancomycin. The isolate resistant to vancomycin was resistant to all antibiotics tested including Quinupristin/dalfopristin (Synercid).

Table 1: Distribution of participants

\begin{tabular}{lc}
\hline Parameter & Description \\
\hline Age years (Mean $=33.7, \mathrm{SD}= \pm 8.7)$ & Frequency $(\%)$ \\
$20-29$ & $75(37.9)$ \\
$30-39$ & $80(40.4)$ \\
$40-49$ & $25(12.6)$ \\
$50-59$ & $18(9.1)$ \\
Sex distribution & \\
Males & $101(51.0)$ \\
Females & $97(49.0)$ \\
Number of years in service (Mean $=7.3, \mathrm{SD}= \pm 7.8)$ & \\
$\leq 5$ & $141(71.2)$ \\
$>5$ & $57(28.8)$ \\
Number of years in critical unit (Mean $=33.7, \pm \mathrm{SD}=8.7)$ \\
$\leq 5$ & $159(80.3)$ \\
$>5$ & $39(19.7)$ \\
Socioeconomic class & \\
Upper & $70(35.4)$ \\
Middle & $55(27.8)$ \\
Low & $73(36.9)$ \\
Category of work & \\
Doctors & $69(34.8)$ \\
Nurses & $51(25.8)$ \\
Students & $42(21.2)$ \\
Attendants & $18(9.1)$ \\
Porters & $11(5.6)$ \\
Technicians & $4(2.0)$ \\
Administrative staff & $3(1.5)$ \\
\hline
\end{tabular}

Table 2: Site distribution of MRSA isolates

\begin{tabular}{lc}
\hline Site & Frequency $(\%) \mathrm{n}=198$ \\
\hline Hand & $52(26.3)$ \\
Nose & $79(39.9)$ \\
Both hand and nose & $25(12.6)$ \\
Either hand and nose & $104(52.5)$ \\
\hline
\end{tabular}

Table 3: Hospital units related staff MRSA carriage

\begin{tabular}{lllll}
\hline Unit & $\begin{array}{l}\text { No. } \\
\text { sampled }\end{array}$ & $\begin{array}{l}\text { No. } \\
\text { positive }\end{array}$ & $\begin{array}{l}\text { Hospital unit } \\
\text { related carriage }(\%)\end{array}$ & $\begin{array}{l}\text { Total carriage } \\
(\%) \mathrm{n}=198\end{array}$ \\
\hline NICU & 88 & 44 & 50.0 & 42.3 \\
ICU & 70 & 41 & 58.6 & 39.4 \\
DRU & 40 & 19 & 47.5 & 18.3
\end{tabular}

Legend: ICU: Intensive Care Unit (for adults); NICU: Neonatal Intensive Care Unit; DRU: Dialysis/Renal Unit

Table 4: Profession/cadre related distribution of MRSA carriage

\begin{tabular}{lllll}
\hline & & & \multicolumn{2}{l}{ Cadre carriage rate $(\%)$} \\
Cadre & $\begin{array}{l}\text { No. } \\
\text { sampled }\end{array}$ & $\begin{array}{c}\text { No. } \\
\text { positive }\end{array}$ & $\begin{array}{l}\text {--------------- } \\
\text { Within cadre }\end{array}$ & Total $(\mathrm{n}=198)$ \\
\hline Doctors & 69 & 45 & 65.2 & 22.7 \\
Nurses & 51 & 33 & 64.7 & 16.7 \\
Students & 42 & 10 & 23.8 & 5.1 \\
Attendants & 18 & 9 & 50.0 & 4.5 \\
Porters & 11 & 4 & 36.4 & 2.0 \\
Technicians & 4 & 1 & 25.0 & 0.5 \\
Admin. staff & 3 & 2 & 66.7 & 1.0 \\
\hline
\end{tabular}


Am. J. Infect. Dis., 6 (1): 18-23, 2010

Table 5: Antibiotic sensitivity profile of MRSA isolates

\begin{tabular}{|c|c|c|c|c|}
\hline \multirow[b]{2}{*}{ Antibiotics } & \multicolumn{2}{|c|}{ NOSE $\mathrm{n}=79(\%)$} & \multicolumn{2}{|c|}{ HAND $\mathrm{n}=52(\%)$} \\
\hline & Resistant & Sensitive & Resistant & Sensitive \\
\hline Gentamycin & $50(63.3)$ & $29(36.7)$ & $18(34.6)$ & $34(65.4)$ \\
\hline Chloramphenicol & $71(89.9)$ & $8(10.1)$ & $39(75.0)$ & $13(25.0)$ \\
\hline Cotrimoxazole & 78 (98.7) & $1(1.3)$ & $52(100)$ & $0(0.0)$ \\
\hline Erythromycin & $55(69.6)$ & $24(30.4)$ & $49(94.2)$ & $3(5.8)$ \\
\hline Ciprofloxacin & $32(40.5)$ & $47(59.5)$ & $18(34.6)$ & $34(65.4)$ \\
\hline Ceftriazone & $78(98.7)$ & $1(1.3)$ & $38(73.1)$ & $14(26.9)$ \\
\hline Amoxyclavulanate & $8(10.1)$ & $71(89.9)$ & 7 (13.5) & $45(86.5)$ \\
\hline Vancomycin & $1(1.3)$ & 78 (98.7) & $0(0.0)$ & $52(100)$ \\
\hline Synercid & $1(100)$ & $0(0.0)$ & - & - \\
\hline
\end{tabular}

\section{DISCUSSION}

MRSA carriage among healthcare workers involved in the management of critically ill patients at UITH, Ilorin Nigeria according to the result of this study is $52.5 \%$. This is far higher that $4.0 \%$ recorded among healthcare workers at North Shore Hospital in New Zealand (Fadheel et al., 2008) and 1.8\% in Southern India (Mathanraj et al., 2009). Furthermore, the MRSA carriage recorded in this study is not comparable to $4.6 \%$ obtained in a meta-analysis of 127 investigations around the world involving screening of 33, 318 healthcare workers (Albrich and Harbarth, 2008). The differences in the design of these studies such as sample size and method of MRSA identification may account for the disparity in the carriage rate. The paucity of local studies makes it difficult to assess the MRSA status in Nigeria. It may not be surprising if Nigeria is truly endemic for MRSA. Previous local studies (Taiwo et al., 2004; Azeez-Akande et al., 2008; Kesah et al., 2003; Adesida et al., 2005) had been on patient isolates with MRSA prevalence lower than recorded in this study. The very high MRSA carriage recorded in this study however may be related to the absence of infection control policy in the healthcare facility where this study was conducted hence the urgent need for one.

MRSA carriage was particularly high among the Doctors $(65.2 \%)$ and Nurses $(64.7 \%)$. This should be seen as a great challenge because doctors and nurses are the healthcare workers with highest frequency of contact with the patients and the most likely to transmit this superbug. This underscores the necessity for a preventive intervention in our hospital, more importantly as studies has shown nosocomial spread of an MRSA strain harboured in the nose of a nurse in two different newborn nurseries (Sherertz and Bassetti, 2010). Further advantage of eradicating MRSA carried by the hospital staff and institution of effective hospital control policies is in prevention of its transmission to their family members and others in the community. This phenomenon has already been documented elsewhere (Halablab et al., 2009; Ciftci et al., 2007). In addition, the financial implication of handling such hospital and community spread of MRSA is huge for which reason MRSA has been described as a public health issue with economic consequences (Mireille et al., 2007).

The MRSA isolates recovered in this study were not molecularly typed making it difficult to establish the possibility of sharing the same strain in a particular hospital unit or across units. However, the marginal difference in the sensitivity pattern of the nasal and hand MRSA isolates is suggestive of similarity in the organisms colonizing the staff and students hands and nares. A molecular typing of MRSA isolates from healthcare workers in the hospital critical outfits is therefore desired.

The MRSA isolates from this study were resistant to most of the antibiotics tested except ciprofloxacin and amoxyclavulanate indicating how dangerous these isolates could be if transmitted to the critically ill patients. The significantly low level of vancomycin resistance of the MRSA isolates (1 in 198) connotes that in an event of outbreak of hospital MRSA from healthcare workers, vancomycin could be reliably effective. Nevertheless, the spread of the only vancomycin resistant isolate could be tasking since this very isolate is resistant to all antibiotics tested. Furthermore, the ease of availability and the profile of toxicity of vancomycin make prevention a very crucial aspect of the care as it is cheaper and better than cure.

\section{CONCLUSION}

In conclusion, MRSA carriage among healthcare workers involved in the management of critically ill patients at UITH, Ilorin, Nigeria is high. The carriage rate is worse among the doctors and nurses though significant number of medical and nursing students and some other categories of healthcare workers were also carriers. There is need for the development, adoption and enforcement of appropriate control policies in hospitals with many points of critical care like our own where there are no existing or effective MRSA control programs.

\section{REFERENCES}

Adesida, S., H. Boelens, B. Babajide, A. Kehinde and S. Snijders et al., 2005. Major epidemic clones of Staphylococcus aureus in Nigeria. Microb. Drug Resist., 11: 115-121. DOI: 10.1046/j.14690691.2003.00531.x 
Albrich, W.C. and S. Harbarth, 2008. Healthcare workers: Source, vector or victim of MRSA. Lancet Infect. Dis., 8: 289-301. http://linkinghub.elsevier.com/retrieve/pii/S14733099(08)70097-5

Andrews, J.M., 2008. BSAC standardized disc susceptibility testing method (version 7). J. Antimicrob. Chemother., 62: 256-278. http://jac.oxfordjournals.org/cgi/pmidlookup?view $=$ long \&pmid $=18474513$

Azeez-Akande, O., S.J. Utsalo and J. Epoke, 2008. Distribution and antibiotic susceptibility pattern of methicillin-resistant Staphylococcus aureus isolates in a university Teaching hospital in Nigeria. Sahel Med. $\quad$ J., $\quad 11$ : 142-147. http://ajol.info/index.php/smj2/article/view/12989

Bauer, A.W., Q.M.M. Kirby, J.C. Sherns and M. Turik, 1966. Antibiotic susceptibility testing by standardized single disk method. Am J. Clin. Path., 45: 493-496. PMID: 5325707

Brady, B., 2008. MRSA-infected medics allowed to keep working. The Independent. http://www.independent.co.uk/life-style/healthand-wellbeing/health-news/mrsainfected-medicsallowed-to-keep-working-805247.html

Chaix, C., I. Durand-Zaleski, C. Alberti and C. Brun-Buisson, 1999. Control of endemic methicillin-resistant Staphylococcus aureus; a cost-benefit analysis in an intensive care unit. J. Am. Med. Assoc.., 282: 1745-1751. http://jama.amaassn.org/cgi/reprint/282/18/1745

Cheesbrough, M., 2000. District Laboratory Practise in Tropical Countries. Part 2. Cambridge University Press, Cambridge, pp: 62-70.

Ciftci, I.H., R. Koken, A. Bukulmez, M. Ozdemir, B. Safak and Z. Cetinkaya, 2007. Nasal carriage of Staphylococcus aureus in 4-6 age groups in healthy children in Afyonkarahisar, Turkey. Acta Paediat., 96: $\quad 1043-1046 . \quad$ DOI: $10.1111 / \mathrm{j} .1651-$ 2227.2007.00315.x

Fadheel, Z.H., H.E. Perry and R.A. Henderson, 2008. Comparison of Methicillin-Resistant Staphylococcus Aureus (MRSA) carriage rate in the general population with the health-worker population (Clinical report). N. Zealand J. Med. Lab. $\quad$ Sci., $\quad 62$ : http://www.nzimls.org.nz/121.html?articles_id=112

Halablab, M.A., S.M. Hijazi, M.A. Fawzi and G.F. Araj, 2010. Staphylococcus aureus nasal carriage rate and associated risk factors in individuals in the community. Epidemiol. Infect., 138: 702-706. DOI: $10.1017 /$ S0950268809991233
Herwaldt, L.A., 1999. Control of methicilin-resistant Staphylococcus aureus in the hospital setting. Am. J. Med., 106: 11S-18S. DOI: 10.1016/S00029343(98)00350-7

Holmes, A., M. Ganner, S. McGuane, T.L. Pitt, B.D. Cookson and A.M. Kearns, 2005. Staphylococcus aureus isolates carrying Panton-Valentine leucocidin genes in England and Wales: Frequency, characterization and association with clinical disease. J. Clin. Microbiol., 43: 2384-2390. http://jcm.asm.org/cgi/pmidlookup?view=long\&p $\operatorname{mid}=15872271$

Kesah, C., S. Ben Redjeb, T.O. Odugbemi, C.B.S. Boye and N. Dosso et al., 2003. Prevalence of methicillin-resistant Staphylococcus aureus in eight African hospitals and Malta. Clin. Microbiol. Infect., $\quad 9(2): 153-156 . \quad$ DOI: $10.1046 / j .1469-$ 0691.2003.00531.x

Mathanraj, S., S. Sujatha, K. Sivasangeetha and S.C. Parija, 2009. Screening for methicillin-resistant Staphylococcus aureus carriers among patients and health care workers of a tertiary care hospital in Southern India. Indian J. Med. Microbiol., 27: 62-64.

http://www.ijmm.org/text.asp?2009/27/1/62/45173

Mireille, G., L. Pierre-Alexandre, H. Donald and V. Colin, 2007. Methicillin-resistant Staphylococcus aureus: A public health issue with economic consequences. Can. J. Infect. Dis. Med. Microbiol., 18: 27-34. http://www.ncbi.nlm.nih.gov/pmc/articles/PMC254 2887/pdf/jidmm18027.pdf

MRSA., 2010. Guideline for the control of MRSA. MRSA Task Force of the Greater Omaha Area Chapter of the Association for Professionals in Infection Control and Epidemiology, Inc. http://www.goapic.org/MRSA.htm

Sherertz, R.J. and S. Bassetti, 2010. Cloud" Health care workers. 2001. Emerg. Infect. Dis., 7: 241-244. http://www.cdc.gov/ncidod/eid/vol7no2/sherertz.htm

Shorr, A.F., Y.P. Tabak, V. Gupta, R.S. Johannes and L.Z. Liu et al., 2006. Morbidity and cost burden of methicillin-resistant Staphylococcus aureus in early onset ventilator-associated pneumonia. Crit. Care., 10: R97. DOI: 10.1186/cc4934):1-7

Siegel, J.D., E. Rhinehart, M. Jackson and L. Chiarello, 2006. Healthcare infection control practices advisory committee. Management of multidrugresistant organisms in healthcare settings. Atlanta (GA): Centres for Disease Control and Prevention; Management of Multi-drug resistant organism in healthcare settings. http://www.cdc.gov/ncidod/dhqp/pdf/ar/mdroguide line2006.pdf 
Simpson, A.H.R.W., J. Dave and B. Cookson, 2007. The value of routine screening of staff for MRSA. J. Bone Joint Surg., 89: 565-566. http://www.jbjs.org.uk/cgi/reprint/89-B/5/565.pdf

Taiwo, S.S., B.A. Onile and A.A. Akanbi, 2004. Methicilin Resistant Staphylococcus Aureus (MRSA) isolates in Ilorin, Nigeria. Afr. J. Clin. Exp. Microbiol., 5: 189-197. http://ajol.info/index.php/ajcem/article/view/7376/0

Tenover, F.C. and R.P. Gaynes, 2000. The Epidemiology of Staphylococcus Infections. In: Gram-Positive Pathogens, Fischetti, V.A., R.P. Novick, J.J. Ferretti, D.A. Portnoy and J.L. Rood (Eds.). American Society for Microbiology, Washington, DC., pp: 414-421.
Vonberg, P.R., S. Stamm-Balderjahn, S. Hansen, I. Zuschneid and H. Ruden et al., 2006. How Often Do Asymptomatic Healthcare Workers Cause Methicillin-Resistant Staphylococcus aureus Outbreaks? A systematic evaluation. Infect. Control Hospital Epidemiol., 27: 1123-1127. PMID: 17006821

Zahar, J.R., C. Clec'h, M. Tafflet, M. Garrouste-Orgeas and S. Jamali et al., 2005. Is methicillin resistance associated with a worse prognosis in Staphylococcus aureus ventilator-associated pneumonia? Clin. Infect. Dis., 41: 1224-1231. Available at http://www.journals.uchicago.edu/cgibin/resolve?CID36493 